\title{
Template-based synthesis of a formate metal-organic framework/ activated carbon fibre composite for high-performance methane adsorptive separation
}

\author{
Xiao-Wei Liu, ${ }^{[a, b]}$ Jiang-Liang Hu, ${ }^{[a, b]}$ Tian-Jun Sun, ${ }^{*[a]}$ Ya Guo, ${ }^{[a, b]}$ Thomas D. Bennett, ${ }^{*[c]}$ Xin-Yu Ren, ${ }^{[a]}$ \\ and Shu-Dong Wang ${ }^{*[a]}$
}

\begin{abstract}
Simultaneous improvement in adsorption selectivity and capacity for single adsorbents is challenging but counting for much in adsorptive separations. To this end, a formate metal-organic framework and activated carbon fibre composite was synthesized in our work by a simple two-step process, involving homogeneous precipitation of a MOF precursor on an activated carbon fiber, and subsequent template replication. The resultant core-shell composite, ACF@ $\left[\mathrm{Ni}_{3}(\mathrm{HCOO})_{6}\right]$, exhibited optimized adsorption performance both in selectivity and capacity for the separation of $\mathrm{CH}_{4} / \mathrm{N}_{2}$ to most of state-of-the-art adsorbents.
\end{abstract}

Separation of $\mathrm{CH}_{4} / \mathrm{N}_{2}$, whilst desirable for the recovery of methane from different resources and emissions, is rather challenging due to their similar kinetic diameters and the higher polarizability/lower quadrupole moment of $\mathrm{CH}_{4}{ }^{[1]} \mathrm{A}$ myriad of adsorption-based strategies have been applied to the separation though the adsorbents used suffer from low capacities and selectivities, or blockage problems. ${ }^{[1,2]}$ Activated carbon fibres (ACFs) have been suggested as a possible solution owing to their relatively abundant micropores, low polarity and fast adsorption/desorption rates, though they exhibit undesired selectivities due to their wide pore size distributions (PSDs).

More recently, metal-organic frameworks (MOFs), threedimensional networks consisting of inorganic nodes linked by organic ligands, have been proposed for potential application in gas separations. ${ }^{[3]}$ Metal formate frameworks, a specific class of MOFs (Figure 1a), have been shown to exhibit higher selectivities than others owing to their uniform one-dimension micropores and optimal polarizability. ${ }^{[4-6]}$ Overall methane sorption capacities however, need be further enhanced for adsorptive separation. ${ }^{[5,6]}$

For gas separations based on physisorption in absorbents, there exists a trade-off between sorption capacity and selectivity, which is a major barrier to the development of new material candidates. ${ }^{[7]}$ Recent work tactfully addressed the problem in a selection of MOFs by exercising accurate control over pore size and chemistry. ${ }^{[7]}$ In our case, we are up for the challenge by

[a] X.-W. Liu, J.-L. Hu, Dr. T.-J. Sun, Y. Guo, X.-Y. Ren and Prof. Dr. S.-D. Wang

Dalian National Laboratory for Clean Energy, Dalian Institute of Chemical Physics, Chinese Academy of Sciences

457 Zhongshan Road, Dalian 116023, P. R. China

E-mail: wangsd@dicp.ac.cn, suntianjun@dicp.ac.cn

[b] X.-W. Liu, J.-L. Hu, Y. Guo

University of Chinese Academy of Sciences

19 A Yuquan Road, Beijing 100049, P. R. China

[c] Dr. Thomas D. Bennett

Department of Materials Science and Metallurgy, University of Cambridge

27 Charles Babbage Road, Cambridge CB3 OFS, United Kingdom E-mail: tdb35@cam.ac.uk

Supporting information for this article is given in another text simply targeting the synthesis of MOF-ACF composites, in which the high specific selectivities of the former are integrated with the large storage capacities of the latter.

Synthetic methods such as one-pot synthesis, ${ }^{[8]}$ secondary growth, ${ }^{[9]}$ layer by layer assembly and direct self-assembly approaches, ${ }^{[10]}$ have been used to create such composites. In order to circumvent problems caused by the application of mixed powder composites, significant advances have been made in the design of suitable MOF-composite morphologies. Promising strategies include embedding MOFs within polymer matrices, ${ }^{[1]}$ directly hot-pressing reactants together to form coatings, ${ }^{[12]}$ and growing MOFs onto the surface of the substrates by template replication, which is widely used to fabricate higher-order MOFbased architectures but usually requires microwave-assisted synthesis. $^{[13]}$

Core-shell architectures, ${ }^{[14]}$ in which a highly selective MOF layer covers the surface of the ACF and attenuates the wide PSDs, while retaining the overall sorption capacity, appear particularly promising with respect to their macroscopic architectures. In this work, we synthesized a MOF-ACF composite for $\mathrm{CH}_{4} / \mathrm{N}_{2}$ separation through a facile templatebased strategy involving (i) loading of a $\mathrm{Ni}$ precursor on ACF fabric by homogeneous precipitation, and (ii) conversion of this precursor into a $\left[\mathrm{Ni}_{3}(\mathrm{HCOO})_{6}\right]$ MOF through template replication (Figure 1b). The resultant composite was found to exhibit optimized $\mathrm{CH}_{4} / \mathrm{N}_{2}$ selectivities and $\mathrm{CH}_{4}$ sorption capacities to other adsorbents.

$\mathrm{Ni}_{2}(\mathrm{OH})_{2} \mathrm{CO}_{3}$ was selected as a suitable starting precursor as it could be easily obtained via homogeneous precipitation of soluble nickel ions by urea hydrolysis, and also proved to be feasible for the formation of $\left[\mathrm{Ni}_{3}(\mathrm{HCOO})_{6}\right]$ MOF (Figure S1). In a typical experiment, activated carbon fibers were immersed into a clear solution containing nickel sulphate, urea and deionized water, in a 1: 5: 555 molar ratio, and heated to $363 \mathrm{~K}$ for 12 hours in an autoclave. Powder X-ray diffraction (PXRD) performed showed the presence of broad peaks in the product matching those present in both pure ACF and $\mathrm{Ni}_{2}(\mathrm{OH})_{2} \mathrm{CO}_{3}$ (Figure 1c, see more details in $\mathrm{SI}$ ). Scanning electron microscopy (SEM) revealed a dense, cracked outer layer (Figure 2), which is consistent with other work. ${ }^{[15]}$

Precursor conversion was then performed by immersing the above-synthesized ACF@ $\mathrm{Ni}_{2}(\mathrm{OH})_{2} \mathrm{CO}_{3}$ into a formic acid/DMF solution (typically $6.0 \mathrm{wt} \% \mathrm{HCOOH}$ ), and heating to $373 \mathrm{~K}$ in an autoclave for 24 hours. The PXRD pattern of the product, ACF $@\left[\mathrm{Ni}_{3}(\mathrm{HCOO})_{6}\right]$, contained only peaks matching those of pure $\mathrm{ACF}$ and $\left[\mathrm{Ni}_{3}(\mathrm{HCOO})_{6}\right]$ (Figure 1c),${ }^{[16]}$ suggesting the full conversion of nickel carbonate hydroxide to the MOF structure. A uniform coating of $\left[\mathrm{Ni}_{3}(\mathrm{HCOO})_{6}\right]$ on the carbon scaffold is clearly visible (Figure 2c), and its identity as $\mathrm{Ni}_{3}(\mathrm{HCOO})_{6}$ was confirmed by EDS analysis (spectroscopy and corresponding elemental mapping) (Figure S2). The measurements were observed to cause degradation of the MOF layer after relatively 
(a)

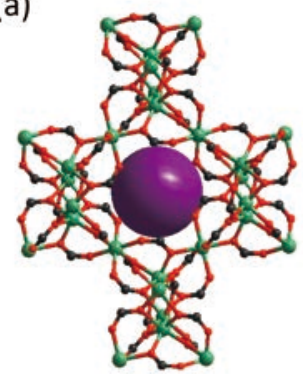

(b)

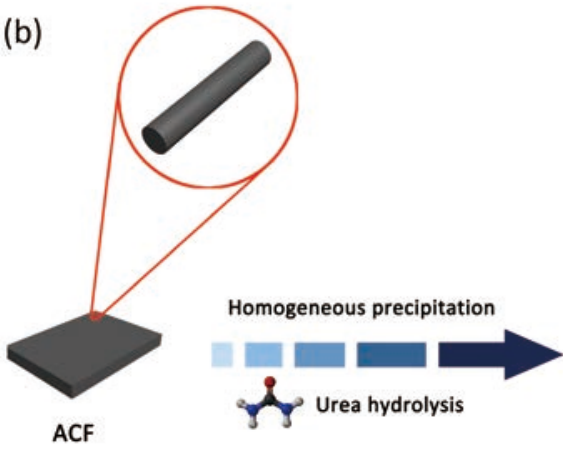

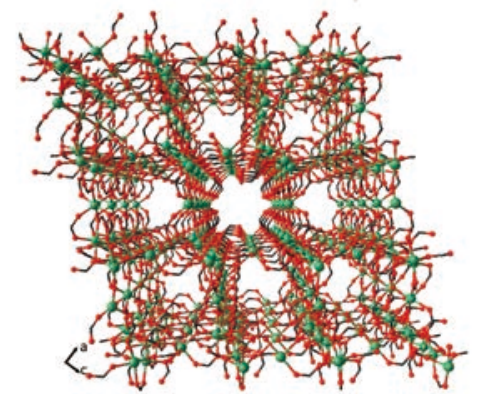

(c)

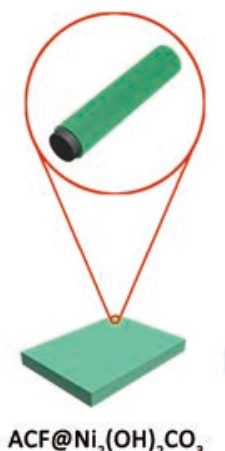

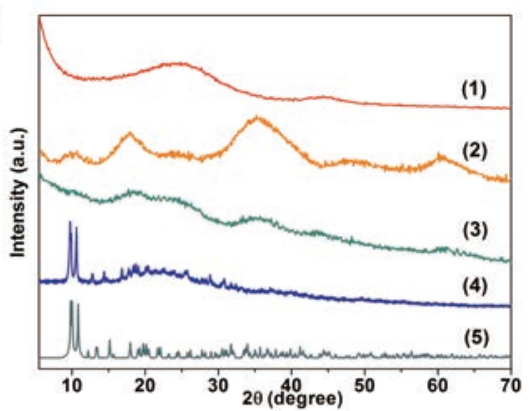

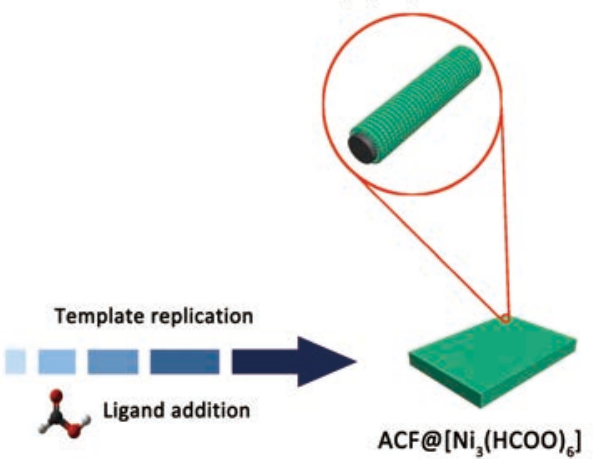

Figure 1. (a) The structure of $\left[\mathrm{Ni}_{3}(\mathrm{HCOO})_{6}\right]$ framework: $\mathrm{Ni}$-centred $\mathrm{NiNi}_{4}$ tetrahedral units with a gas molecule (purple) inside the pore and the unit cell of $\left[\mathrm{Ni}_{3}(\mathrm{HCOO})_{6}\right]$ framework, with one-dimensional zigzag like channels (pore width: ca. $4 \times 5 \AA$ ). The $\mathrm{C}, \mathrm{O}, \mathrm{H}, \mathrm{N}$ and $\mathrm{Ni}$ atoms are represented in black, red, grey, blue and green, respectively ( $\mathrm{H}$ atoms are omitted for clarity here). (b) Schematic of the template synthesis of $A C F @\left[N i_{3}(H C O O)_{6}\right]$. (c) XRD patterns of (1) $A C F$, (2) $\mathrm{Ni}_{2}(\mathrm{OH})_{2} \mathrm{CO}_{3},(3) \mathrm{ACF} @ \mathrm{Ni}_{2}(\mathrm{OH})_{2} \mathrm{CO}_{3},(4) \mathrm{ACF} @\left[\mathrm{Ni}_{3}(\mathrm{HCOO})_{6}\right]$ and (5) the simulated pattern of $\left[\mathrm{Ni}_{3}(\mathrm{HCOO})_{6}\right]$ from ref [16].

long-term exposure to the high-energy electrons (Figure S3), which is consistent with the susceptibility of MOFs in general to radiation damage. ${ }^{[17]}$ The transformation process could also be followed through optical imaging (Figure S4).

Interestingly, although coatings with less macroscopic defects could be prepared through use of milder hydrothermal conditions and reducing starting reagent concentration, the resultant thin layer of nickel precursor failed to supply enough nickel ions for coordination in the second step, giving birth to a discontinuous layer and sparsely situated MOF crystals on the
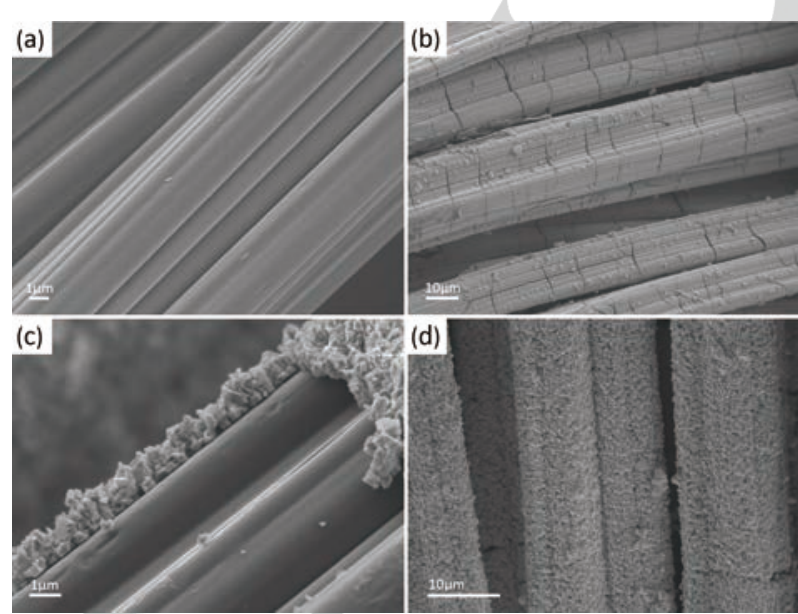

Figure 2. SEM images of (a) pure $A C F$, (b) $A C F @ N_{2}(O H)_{2} \mathrm{CO}_{3}$, (c) a sideview of the MOF layer on ACF and (d) ACF@ $\left[\mathrm{Ni}_{3}(\mathrm{HCOO})_{6}\right]$. surface of the ACF (Figure S5). However, the presence of cracks in the nickel precursor layer was not deemed to greatly affect the quality of the final ACF@ $\left[\mathrm{Ni}_{3}(\mathrm{HCOO})_{6}\right]$ material (Figure 2). This independence of the final coating quality upon the cracks in initial nickel precursor, is attributed to the greater extent of MOF crystallization and growth at these defect sites in the second step ${ }^{[18]}$ Nevertheless, attempts to fabricate a thicker homogeneous MOF layer were found companied by an increase in cracking (Figure S6). Besides, such attempts may also have led to undesirable overall methane sorption capacities (Figure S7), given the lower capacity of the MOF layer than the ACF layer (Figure 3b).

Argon adsorption isotherms of the materials are displayed in Figure 3a. All exhibit Langmuir-type characteristics, which suggest uniform pores of micro-porosity. Isotherms of ACF and $\mathrm{ACF} @\left[\mathrm{Ni}_{3}(\mathrm{HCOO})_{6}\right]$ reveal a minor hysteresis, indicating a small minority of mesopores inside. Based on the isotherms, the textual properties of the porous structure of the samples were calculated and listed in Table 1. Notably, the pore volume and specific surface area of MOF-ACF composite are close to those of pristine ACF and much higher than those of the pristine MOF. The lower porosity of the composite compared to the physically mixed sample is attributed to the partial blockage of the large ACF pores by the MOF crystals. This synergistic effect of combining the two components is also evident from the narrower PSD of the composite material (Figure S8). A drastic reduction in pores larger than $1 \mathrm{~nm}$ was observed upon coating ACF with $\left[\mathrm{Ni}_{3}(\mathrm{HCOO})_{6}\right]$. In stark contrast, the mixed sample exhibited pores representative of those in the pristine separate components, and most of the large pores still existed. 
Table 1. Textual properties of the porous structures of $A C F,\left[\mathrm{Ni}_{3}(\mathrm{HCOO})_{6}\right]$, $\mathrm{ACF} @\left[\mathrm{Ni}_{3}(\mathrm{HCOO})_{6}\right]$ and the mixed sample based on argon adsorption isotherms $^{\text {a }}$

\begin{tabular}{ccccc}
\hline Adsorbents & $\begin{array}{c}\mathrm{S}_{\mathrm{BET}} \\
\left(\mathrm{m}^{2} \mathrm{~g}^{-1}\right)\end{array}$ & $\begin{array}{c}\mathrm{S}_{\text {Langmuir }} \\
\left(\mathrm{m}^{2} \mathrm{~g}^{-1}\right)\end{array}$ & $\begin{array}{c}\mathrm{V}_{\mathrm{t}} \\
\left(\mathrm{cm}^{3} \mathrm{~g}^{-1}\right)\end{array}$ & $\begin{array}{c}\mathrm{V}_{\text {mic }} \\
\left(\mathrm{cm}^{3} \mathrm{~g}^{-1}\right)\end{array}$ \\
\hline $\mathrm{ACF}$ & 1324 & 1613 & 0.573 & 0.473 \\
$\left.\mathrm{ACF}(\mathrm{HCOO})_{6}\right]^{\mathrm{b}}$ & 284 & 337 & 0.130 & 0.092 \\
$\mathrm{MOF}^{\mathrm{N}}\left[\mathrm{Ni}_{3}(\mathrm{HCOO})_{6}\right]$ & 1053 & 1276 & 0.453 & 0.381 \\
$\mathrm{MOF}^{\mathrm{C}}$ & 1102 & 1327 & 0.469 & 0.400 \\
\hline
\end{tabular}

a See more calculating details for the textual properties in characterization section in SI; ${ }^{b}$ values may slightly vary from previous work because of the differences in after-treatment. ${ }^{c}$ the physically mixed samples with 22 wt\% MOF. ${ }^{d}$ theoretical values calculated from the pure components by the ratio.

Adsorption isotherms of $\mathrm{CH}_{4}$ and $\mathrm{N}_{2}$ were measured at 298 $\mathrm{K}$ and $308 \mathrm{~K}$ (Figure $\mathbf{3 b}$ and Figure S9). All samples preferentially adsorbed $\mathrm{CH}_{4}$ over $\mathrm{N}_{2}$, which is ascribed to the higher polarizability of the former $\left(26 \times 10^{-25} \mathrm{~cm}^{-3}\right.$ vs. $17.6 \times 10^{-25}$ $\left.\mathrm{cm}^{-3}\right) \cdot{ }^{[1]}$ At 1 bar, the $\mathrm{CH}_{4}$ sorption capacity of ACF@ $\left[\mathrm{Ni}_{3}(\mathrm{HCOO})_{6}\right]$ was significantly higher (ca. $\left.30 \%\right)$ than that of the pure $\left[\mathrm{Ni}_{3}(\mathrm{HCOO})_{6}\right]$ (Figure 4). The composite also exhibited a comparable $\mathrm{CH}_{4}$ sorption capacity to that of the pure ACF and

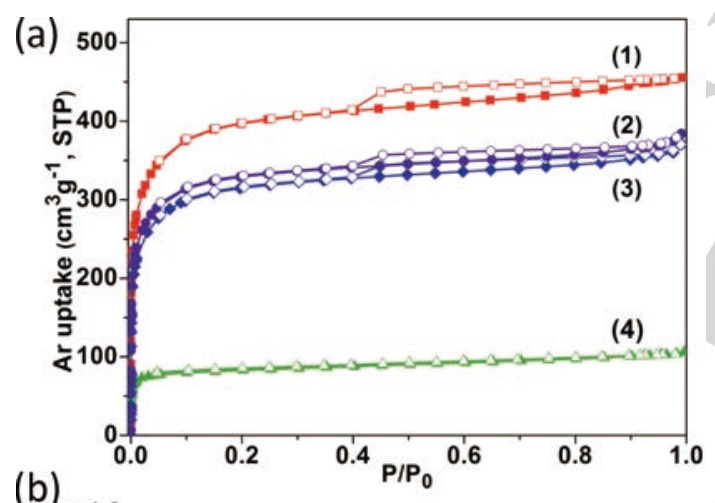

(b)

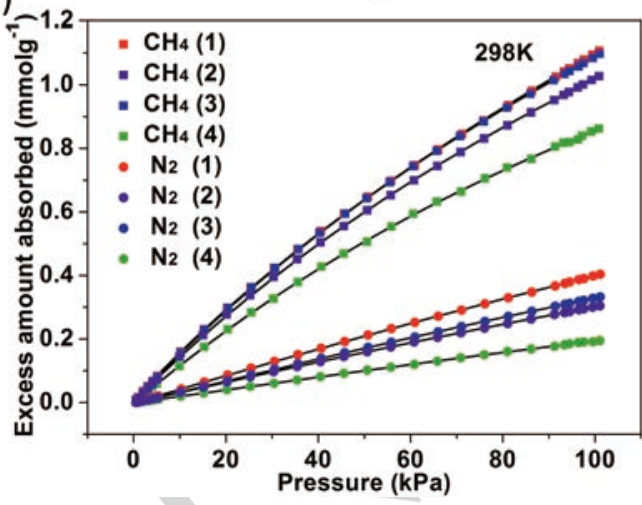

Figure 3. (a) Argon adsorption/desorption isotherms at $87 \mathrm{~K}$ and (b) pure gas adsorption isotherms of $\mathrm{CH}_{4}$ and $\mathrm{N}_{2}$ at $298 \mathrm{~K}$. Sample labelling as follows: (1) ACF, (2) the physically mixed sample with 22 wt\% MOF, (3) ACF@ $\left[\mathrm{Ni}_{3}(\mathrm{HCOO})_{6}\right]$ and $(4)\left[\mathrm{Ni}_{3}(\mathrm{HCOO})_{6}\right]$ (Solid lines in b: Langmuir-Freundlich model, the linearity of fitting is 0.999 ).

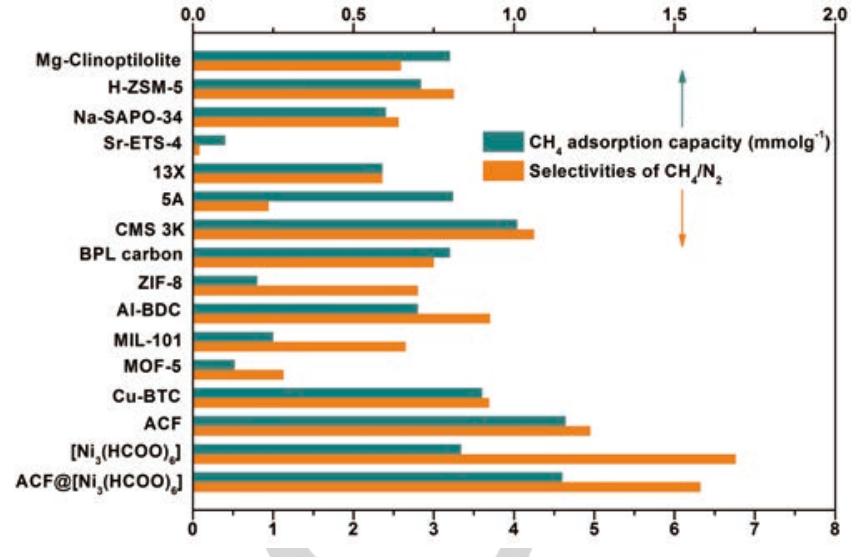

Figure 4. The $\mathrm{CH}_{4} / \mathrm{N}_{2}$ equilibrium selectivities and the $\mathrm{CH}_{4}$ sorption capacity of some state-of-the-art adsorbents at $298 \mathrm{~K}$ (see more samples and details in Table S2).

the mixed sample over the pressure range.

The pure gas adsorption isotherms are well fitted with the Langmuir-Freundlich model (parameters given in Table S1), and the Henry's law selectivities of $\mathrm{CH}_{4} / \mathrm{N}_{2}$ are shown in Figure 4. As discussed in previous work, the wide pore distribution of the adsorbents would deteriorate the $\mathrm{CH}_{4} / \mathrm{N}_{2}$ selectivity, as the pores, especially the mesopores, could be large enough for both the adsorbate molecules to freely penetrate, and thus be less selective for the separation. ${ }^{[5,19]}$ Therefore, the higher selectivity of $A C F @\left[\mathrm{Ni}_{3}(\mathrm{HCOO})_{6}\right]$ compared to the pure ACF and the mixed sample is ascribed to the narrower PSD of the former, which is close to the diameters of $\mathrm{CH}_{4}$ and $\mathrm{N}_{2}-0.380 \mathrm{~nm}$ and $0.364 \mathrm{~nm}$,

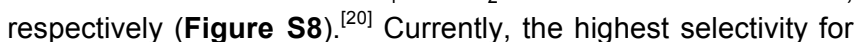
the separation $\left(\mathrm{N}_{2} / \mathrm{CH}_{4}\right)$ reported by far is ca. 13 , of Sr-ETS-4, which is based on a steric mechanism, ${ }^{[21]}$ though the overall $\mathrm{CH}_{4}$ sorption capacity remains modest. Most of other state-of-the-art adsorbents' selectivities for $\mathrm{CH}_{4} / \mathrm{N}_{2}$ are below 5 (Figure 4). ${ }^{[2]}$

In conclusion, we have fabricated a higher-order MOFcarbon composite via a facile two-step strategy employing homogeneous precipitation and template replication. The resultant core-shell composite, ACF@ $\left[\mathrm{Ni}_{3}(\mathrm{HCOO})_{6}\right]$, combining the gas adsorption selectivities of formate MOFs and overall sorption capacities of ACFs, revealed excellent adsorption performance with a high $\mathrm{CH}_{4} / \mathrm{N}_{2}$ selectivity (up to 6.2) as well as $\mathrm{CH}_{4}$ sorption capacity (up to $1.1 \mathrm{mmolg}^{-1}$ ) at $298 \mathrm{~K}$ and 1 bar. The composite exhibited a $\sim 25 \%$ increase in selectivity compared to pure ACF, and a $\sim 30 \%$ increase in sorption capacity compared to the pure MOF.

We believe the concept utilized in our work could be applied to combine other adsorbents deficient in some aspects but efficient in other, and the facile template strategy we demonstrated might also be scalable for the synthesis of other MOFs on other substrates.

\section{Experimental Section}

\section{Materials}

All chemicals were used as obtained from commercial suppliers (Sinopharm and others). ACF fabric, with single fibre diameter of $10-20 \mu \mathrm{m}$, was first washed with deionized water repeatedly and 
then immersed into hydrochloric acid over night to remove the metal impurities. After washing with water to neutralization, the purified ACF was dried at $393 \mathrm{~K}$ in air for $6 \mathrm{~h}$.

\section{Synthesis of $\mathrm{ACF} @ \mathrm{Ni}_{2}(\mathrm{OH})_{2} \mathrm{CO}_{3}$}

A piece of ACF fabric was placed in a polytetrafluoroethylene (PTFE) liner and immersed into a clear solution containing nickel sulfate, urea and deionized water. In a typical experiment, the molar ratio of $\mathrm{Ni}^{2+}: \mathrm{CO}\left(\mathrm{NH}_{2}\right)_{2}: \mathrm{H}_{2} \mathrm{O}$ was 1: 5: $555\left(\mathrm{Ni}^{2+}: 0.005\right.$ $\mathrm{mol})$. Then the liner containing the mixtures was put in an autoclave, sealed and heated at $363 \mathrm{~K}$ for $12 \mathrm{~h}$. Afterwards, the chemically coated ACF was taken out, washed with deionized water and dried. Pure $\mathrm{Ni}_{2}(\mathrm{OH})_{2} \mathrm{CO}_{3}$ was prepared via the same experimental procedure, except for adding ACF.

\section{Synthesis of $A C F @\left[\mathrm{Ni}_{3}(\mathrm{HCOO})_{6}\right]$}

$\mathrm{HCOOH}$ and DMF (typically $2 \mathrm{ml}$ and $40 \mathrm{ml}, \mathrm{HCOOH}: 6.0 \mathrm{wt} \%$ ) were mixed at room temperature and transferred into a Teflon autoclave, before immersion of $\mathrm{ACF} @ \mathrm{Ni}_{2}(\mathrm{OH})_{2} \mathrm{CO}_{3}$ into the solution. Afterwards, the autoclave was sealed and heated to $373 \mathrm{~K}$ for $24 \mathrm{~h}$. After cooling naturally, the product was taken out washed with DMF and acetone for several times, and dried in vacuum. The loading of $\left[\mathrm{Ni}_{3}(\mathrm{HCOO})_{6}\right] \mathrm{MOF}$ based on the composite is ca. $22 \mathrm{wt} \%$.

Pure $\left[\mathrm{Ni}_{3}(\mathrm{HCOO})_{6}\right]$ was also synthesized according to existing protocols. ${ }^{[5]}$ The resultant green crystals were washed with DMF, and then immersed in methanol for $48 \mathrm{~h}$ (decanted and replenished every $16 \mathrm{~h}$ ) to fully exchange the organic solvent molecules left inside the frameworks. $\left[\mathrm{Ni}_{3}(\mathrm{HCOO})_{6}\right]$ was also produced from the above-synthesized $\mathrm{Ni}_{2}(\mathrm{OH})_{2} \mathrm{CO}_{3}$ under similar synthetic conditions to further confirm the feasibility of template synthesis. The physically mixed sample of $\left[\mathrm{Ni}_{3}(\mathrm{HCOO})_{6}\right]$ and ACF were obtained by directly mixing the $\left[\mathrm{Ni}_{3}(\mathrm{HCOO})_{6}\right]$ powders and the crushed ACF powders with a weight ratio of 22:78.

See characterization section and pure gas adsorption measurement details in SI.

\section{Acknowledgements}

This work is supported by the NSFC China (21476231). The authors are also grateful to Dr. Xiao-Fei Yang for his help in drawing.

Keywords: Metal-organic framework - activated carbon fibre template replication $\cdot$ core-shell architecture $\cdot$ adsorption

[1] R. T. Yang, Adsorbent: Fundametals and Applications, John Wiley \& Sons, Hoboken, 2003; M. Tagliabue, D. Farrusseng, S. Valencia, S. Aguado, U. Ravon, C. Rizzo, A. Corma, C. Mirodatos, Chem. Eng. J. 2009, 155, 553-566; K. Lee, W. C. Isley, A. L. Dzubak, P. Verma, S. J. Stoneburner, L. C. Lin, J. D. Howe, E. D. Bloch, D. A. Reed, M. R. Hudson, C. M. Brown, J. R. Long, J. B. Neaton, B. Smit, C. J. Cramer D. G. Truhlar, L. Gagliardi, J. Am. Chem. Soc. 2014, 136, 698-704.

[2] T. E. Rufford, S. Smart, G. C. Y. Watson, B. F. Graham, J. Boxall, J. C. Diniz da Costa, E. F. May, J. Pet. Sci. Eng. 2012, 94-95, 123-154; J. A. C. Silva, A. Ferreira, P. A. P. Mendes, A. F. Cunha, K. Gleichmann, A. E. Rodrigues, Ind. Eng. Chem. Res. 2015, 54, 6390-6399.

[3] J. R. Li, J. Sculley, H. C. Zhou, Chem. Rev. 2012, 112, 869-932; H. Furukawa, K. E. Cordova, M. O’Keeffe, O. M. Yaghi, Science 2013, 341, 1230444.
[4] Z. M. Wang, B. Zhang, Y. J. Zhang, M. Kurmoo, T. Liu, S. Gao, H. Kobayashi, Polyhedron 2007, 26, 2207-2215; K. H. Li, D. H. Olsan, J. Y. Lee, W. H. Bi, K. Wu, T. Yuen, Q. Xu, J. Li, Adv. Funct. Mater. 2008, 18, 2205-2214.

[5] X. Ren, T. Sun, J. Hu, S. Wang, Microporous Mesoporous Mater. 2014 186, 137-145; X. Ren, T. Sun, J. Hu, S. Wang, RSC Adv. 2014, 4 42326-42336.

[6] J. Hu, T. Sun, X. Liu, S. Zhao, S. Wang, Microporous Mesoporous Mater. 2016, 225, 456-464.

[7] X. Cui, K. Chen, H. Xing, Q. Yang, R. Krishna, Z. Bao, H. Wu, W. Zhou, X. Dong, Y. Han, B. Li, Q. Ren, M. J. Zaworotko, B. Chen, Science 2016, 353, 141-144; A. Cadiau, K. Adil, P. M. Bhatt, Y. Belmabkhout, M. Eddaoudi, Science 2016, 353, 137-140.

[8] S. J. Yang, J. Y. Choi, H. K. Chae, J. H. Cho, K. S. Nahm, C. R. Park, Chem. Mater. 2009, 21, 1893-1897; C. Petit, T. J. Bandosz, Adv. Mater. 2009, 21, 4753-4757; C. Petit, T. J. Bandosz, J. Colloid Interface Sci. 2015, 447, 139-151; X. W. Liu, T. J. Sun, J. L. Hu, S. D. Wang, J. Mater. Chem. 2016, 4, 3584-3616.

[9] L. Dumee, L. He, M. Hill, B. Zhu, M. Duke, J. Schutz, F. S. She, H. T. Wang, S. Gray, P. Hodgson, L. X. Kong, J. Mater. Chem. 2013, 1, 9208-9214; D. Qian, C. Lei, G.-P. Hao, W.-C. Li, A.-H. Lu, ACS Appl. Mater. Interfaces 2012, 4, 6125-6132.

[10] X. Wang, Q. X. Wang, Q. H. Wang, F. Gao, F. Gao, Y. Z. Yang, H. X. Guo, ACS Appl. Mater. Interfaces 2014, 6, 11573-11580; A. Huang, Q. Liu, N. Wang, Y. Zhu, J. Caro, J. Am. Chem. Soc. 2014, 136, 1468614689.

[11] T. Rodenas, I. Luz, G. Prieto, B. Seoane, H. Miro, A. Corma, F. Kapteijn, F. X. Llabrés i Xamena, J. Gascon, Nat. Mater. 2015, 14, 4855; Z. Zhang, H. T. H. Nguyen, S. A. Miller, S. M. Cohen, Angew. Chem. Int. Ed. 2015, 54, 6152-6157; Angew. Chem. 2015, 127, 6250-6255; Y. Zhang, S. Yuan, X. Feng, H. Li, J. Zhou, B. Wang, J. Am. Chem. Soc. 2016, 138, 5785-5788.

[12] Y. Chen, S. Li, X. Pei, J. Zhou, X. Feng, S. Zhang, Y. Cheng, H. Li, R. Han, B. Wang, Angew. Chem. Int. Ed. 2016, 55, 3419-3423; Angew. Chem. 2016, 128, 3480-3484.

[13] J. Reboul, S. Furukawa, N. Horike, M. Tsotsalas, K. Hirai, H. Uehara, M. Kondo, N. Louvain, O. Sakata, S. Kitagawa, Nat. Mater. 2012, 11, 717 723; K. Okada, R. Ricco, Y. Tokudome, M. J. Styles, A. J. Hill, M. Takahashi, P. Falcaro, Adv. Funct. Mater. 2014, 24, 1969-1977; S. M. Meckler, C. Li, W. L. Queen, T. E. Williams, J. R. Long, R. Buonsanti, D. J. Milliron, B. A. Helms, Chem. Mater. 2015, 27, 7673-7679.

[14] J. Ren, N. M. Musyoka, H. W. Langmi, B. C. North, M. Mathe, X. Kang, Int. J. Hydrogen Energy 2014, 39, 14912-14917; L. Li, X. L. Liu, M. Gao, W. Hong, G. Z. Liu, L. Fan, B. Hu, Q. H. Xia, L. Liu, G. W. Song, Z. S. Xu, J. Mater. Chem. 2014, 2, 1795-1801.

[15] H. Chen, Y. Kang, F. Cai, S. Zeng, W. Li, M. Chen, Q. Li, J. Mater. Chem. 2015, 3, 1875-1878.

[16] Z. Wang, B. Zhang, M. Kurmoo, M. A. Green, H. Fujiwara, T. Otsuka, H. Kobayashi, Inorg. Chem. 2005, 44, 1230-1237.

[17] A. A. Talin, A. Centrone, A. C. Ford, M. E. Foster, V. Stavila, P. Haney, R. A. Kinney, V. Szalai, F. El Gabaly, H. P. Yoon, F. Léonard, M. D. Allendorf, Science 2014, 343, 66-69.

[18] R. Ameloot, L. Stappers, J. Fransaer, L. Alaerts, B. F. Sels, D. E. De Vos, Chem. Mater. 2009, 21, 2580-2582; R. Ameloot, F. Vermoortele, W. Vanhove, M. B. J. Roeffaers, B. F. Sels, D. E. De Vos, Nat. Chem. 2011, 3, 382-387.

[19] J. Hu, T. Sun, X. Liu, Y. Guo, S. Wang, RSC Adv. 2016, 6, 6403964046.

[20] D. W. Beck, Zeolite Molecular Sieves, John Wiley \& Sons, New York 1974

[21] S. M. Kuznicki, V. A. Bell, S. Nair, H. W. Hillhouse, R. M. Jacubinas, C M. Braunbarth, B. H. Toby, M. Tsapatsis, Nature 2001, 412, 720-724.

For internal use, please do not delete. Submitted_Manuscript 


\section{COMMUNICATION}

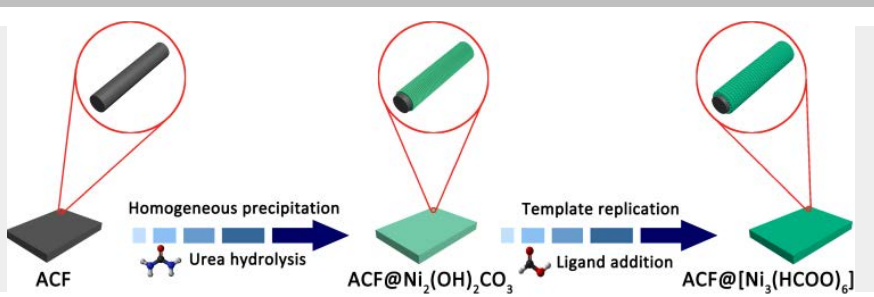

A novel formate metal-organic framework and activated carbon fibre composite was fabricated through a facile two-step strategy involving homogeneous precipitation and template replication. The resultant core-shell composite, ACF@ $\left[\mathrm{Ni}_{3}(\mathrm{HCOO})_{6}\right]$, exhibited superior adsorption performance both in selectivity and capacity for the separation of $\mathrm{CH}_{4} / \mathrm{N}_{2}$ to most of other state-of-the-art adsorbents.
Xiao-Wei Liu, Jiang-Liang Hu, Tian-Jun Sun, ${ }^{*}$ Ya Guo, Thomas D. Bennett, ${ }^{*}$ XinYu Ren, and Shu-Dong Wang*

\section{Page No. - Page No.}

Template-based synthesis of a formate metal-organic framework/ activated carbon fibre composite for high-performance methane adsorptive separation 